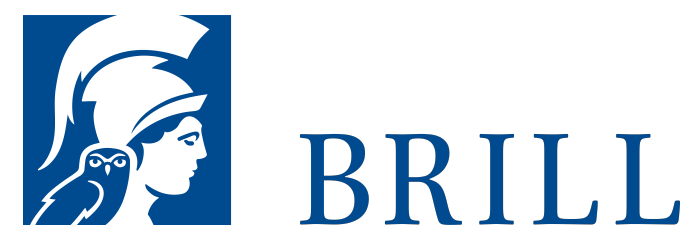

\title{
Projektives Bewusstsein
}

Th. Metzingers Selbstmodelltheorie und J. G. Fichtes

\section{Wissenschaftslehre}

\section{Author: Patrick Grüneberg}

Bewusstsein ist nicht ohne Grund eines der grundlegenden Themen philosophischer Forschung: Es bildet den Kristallisationspunkt, in dem sich die intime Sphäre unserer Persönlichkeit im Schnittfeld mit radikal Anderem artikuliert. Dabei kommt dem subjektiven Bezug auf eine objektive Wirklichkeit, sprich auf uns selbst wie auf unsere natürliche und soziale Umgebung, eine zentrale Funktion zu. Aufgrund seiner Selbstverständlichkeit wird dieser Ausgriff auf die Wirklichkeit jedoch in repräsentationalistischen Ansätzen, die einen Großteil aktueller Bewusstseinstheorie ausmachen, häufig unhinterfragt vorausgesetzt. Dieses Buch entwickelt demgegenüber einen relationalen Erklärungsansatz, der diese Selbstverständlichkeit unserer Selbst- und Weltbezüge in den Mittelpunkt der Betrachtung stellt. In kritischer Auseinandersetzung mit Th. Metzingers Selbstmodelltheorie und im Rekurs aufJ.G. Fichtes späte Wissenschaftslehre entsteht so die Konzeption eines projektiven Bewusstseins. Der damit einhergehende Fokus auf die Entstehung objektiver Wirklichkeit im Bewusstsein erlaubt es, den subjektiven Charakter unseres Bewusstseins besser verständlich zu machen.

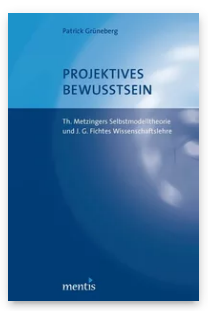

Pages: 264

Seiten

Language:

German

Subjects:

General,

Philosophy

Publisher: Brill | mentis

E-Book (PDF)

Released online:

11 Nov 2013

ISBN: 978-3-

89785-982-1

List price

Paperback

Publication date:

11 Nov 2013

ISBN: 978-3-

89785-834-3

List price 
For more information see brill.com

Order information: Order online at brill.com +44330 333 0049 | customerservices@brill.com Submission information: brill.com/authors

Titles published by Brill | Fink, Brill | mentis or Brill | Schöningh: +49(o)715413279216| brill@brocom.de 